\title{
The Study on the Impact of the Early Rehabilitation and Nursing Intervention on the Opponent Injury Hand Function Recovery
}

\author{
Yun Ma ${ }^{1, a}$, Yan Zhao ${ }^{2,}$, Jianshu Cheng ${ }^{3}$,Yeben Wang ${ }^{4}$ \\ ${ }^{1}$ Department of Outpatient, Third People's Hospital of Jinan, Jinan, 250132, China. \\ ${ }^{2}$ Department of hand Surgery, Third People's Hospital of Jinan, Jinan, 250132, China. \\ ${ }^{3}$ Department of Operating room, Third People's Hospital of Jinan, Jinan, 250132, China. \\ ${ }^{4}$ Department of hand Surgery, Third People's Hospital of Jinan, Jinan, 250132, China. \\ ayunma@126.com
}

*Corresponding author zhao666@163.com

Keywords: Early rehabilitation; Nursing intervention; Hand trauma; Hand function; Restore

\begin{abstract}
To observe and investigate the influence of system early rehabilitation and nursing intervention on the recovery of the injury hand function. Methods: We select 32 cases of hand trauma patients after the surgery as observation group from August 2012 to August 2014, and postoperative 2 day of the early rehabilitation treatment and nursing intervention; We select 32 cases of hand trauma after surgery in the same period, and the patients are as control group, who were used the conventional nursing methods, and to observe two groups of patients with hand function recovery, and comparative analysis. Results: The observation group by the early group and other various thumb function and grip strength and FIM scores were better than control group $(\mathrm{P}<$ 0.05), the recovery refers to the function of two groups of comparison, the observation group is better than that of control group and observation group 4 weeks after the nursing intervention of rehabilitation exercise adherence were superior to control group, $\mathrm{P}<0.05$ ). Conclusion: The hand trauma after timely surgical treatment is the prerequisite of hand function recovery; physical factors, sport therapy, homework therapy, and rehabilitation project of early intervention can improve the activity, and promote the recovery of hand function, worthy of clinical popularization and application.
\end{abstract}

\section{Introduction}

The hand trauma patients with postoperative rehabilitation exercise is one aspect of the larger effects on the prognosis, and the process of rehabilitation exercise can cause not only the patient's discomfort, and also to patient endurance requirement is higher, so the rehabilitation of the patients with exercise adherence of intervention is of Paramount importance, and considering the patients' rehabilitation exercise adherence not only affected by the patient's own and the degree of social support, the influence of nursing intervention for patients is larger, so focus on selecting nursing mode. In recent years, the proportion of hand trauma is occurred present a rising trend year by year. Hand trauma, although little endanger patient's life, however, in the process of to the actual anatomy, the anatomy of the link is often more complex, care little when will easy to left hand functional disorder, will seriously affect the patient's actual life and work. Therefore, should pay attention to strengthen the opponents' trauma patients with postoperative rehabilitation care and functional exercise guidance. In this article we will strengthen the nursing intervention opponents' trauma patients with postoperative rehabilitation exercise adherence are analyzed, the influence of specific reports as follows. 


\section{Materials and Methods}

\section{Materials}

Selection in August 2012 to August 2014 of 32 cases of hand trauma after surgery, patients as observation group, women in 12 cases, 20 cases men, aged 18 to 60 , the average $(28.3 \pm 5.2)$ years of age, operation time was 1.0 to $8.4 \mathrm{~h}$, h average (4.2 \pm 1.8$)$; Crush injury of 20 patients, 14 cases degloving injury, other 8 cases. Selection in the same period of 32 cases of hand trauma after surgery, patients as control group, 13 cases of women, men, 19 cases, aged 20 to 60 years, the average $(29.4 \pm 4.5)$ years of age, operation time was 1.2 to $7.8 \mathrm{~h}$, $\mathrm{h}$ average $(4.1 \pm 1.6)$; The crush injury 19 cases, 13 cases of degloving injury, other 10 cases. Two groups of patients are no significant differences in age, sex and disease, comparable.

\section{Methods}

Observation group 2 days early rehabilitation treatment and nursing intervention; Control group using conventional care method, observe two groups of patients with hand function recovery, and comparative analysis.

\section{Self-evaluation of anxiety scale (SAS) and depression self rating scale (SDS) criteria}

(1) the self-evaluation of anxiety scale (SAS) : according to the China frequently touched as a result, the SAS norm of the boundary value of 50 points, including $50 \sim 59$ were divided into mild anxiety, $60 \sim 69$ were divided into mild anxiety, more than 70 points as severe anxiety. (2), depression self rating scale (SDS) : SDS scale included 20 items, each item shall be carried out in accordance with the grade $1 \sim 4$ grades, total score is 20 to 80 points, will be the total score multiplied by 1.25 norm can be obtained if the standard score is high, it means that the more severe depression, specific standards for the division of depression: SDS 50 points or more depression, 50 $\sim 59$ mild depression, $60 \sim 69$ divided into moderate depression, divided into severe depression 70 or higher. After questionnaire in patients with the consent of the consent, unite by the investigators, also explain the questionnaires and fill in by the patient himself.

\section{Statistical processing}

With mathematical statistics software SPSS19.0 for data collection and statistical analysis, and chi-square test, $\mathrm{P}<0.05$, significant difference has statistical significance.

\section{The Care Methods}

\section{The Rehabilitation nursing methods}

(1) The health education of rehabilitation nursing method, cooperate with the treatment. By the competent nurses, to the hospital health education, discharge considerations and other related content, mainly including diet guidance, rehabilitation exercise, drug use and the matters needing attention, special inspection or preoperative and postoperative considerations, review and matters needing attention after discharge and other related content, to guide the patient and family to master relevant knowledge, cooperate with treatment. (2) Psychological nursing is the bridge closer distance between nurses and patients. To high qualification nurses' psychological consultant training, through to the patients' psychological communication, face-to-face communication, will find the problems and give feedback to departments, and doctors, patients' trust, understanding, even closer relationship between nurses and patients.

\section{The postoperative functional exercise method}

The functional exercise guidance method is the basis of rehabilitation, but unreasonable functional exercise can cause adverse consequences, and even surgery failure., therefore, should be carried out in medical staff under the guidance of functional exercise, and done through active or passive activity, postoperative under the effective fixed, when the condition permission, early 
functional exercise, finger to promote blood circulation, reduce swelling, prevent muscle atrophy, joint rigidity, tendon adhesions and other complications.

\section{The psychological intervention}

Because suddenly appeared after the injury in patients with hand activities inconvenience, generally there is fear and psychological barriers, worry about prognosis and recovery of hand function. Nurse should be based on the status of each patient, detailed psychological treatment plan. Through timely communication and good attitude, won the trust of the patients timely grasp the psychological condition of the patients, and relieve the psychological burden to eliminate negative mentality, such as anxiety, fear, through the introduction of previous treatment to the patients with successful cases, the state in accordance with the doctor's advice to patients under the condition of active treatment, can obtain good therapeutic effect to enhance their confidence and treatment compliance.

\section{The health mission}

(1) The hospital mission: nurses in patients admitted to hospital to show its hand surgery related matters needing attention, and help them master; To introduce the doctor familiar with patients when they are back to the ward patients in the hospital environment to adapt it quickly to the hospital, adjust the mentality to the best condition to accept treatment. (2) The mission: postoperative patients after surgery back ward, the nurse should take the initiative to ask their needs, and postoperative considerations. (3) The medical mission: because the patients know about drug use is not usually nurse need to inform the patients before treatment of the therapeutic effect of drugs and drug use precautions and possible adverse reactions in patients with understanding the resources under the condition of treatment at the same time also can enhance the understanding of disease and control patients. (4) for discharge, the nurse should give timely guidance after discharge from hospital visit time, self care and diet attention to patients and their families for explanation and inform about rehabilitation and functional exercise after discharge the contact method and the matters needing attention to return, once appear unexpected circumstances, instruct patients contact responsibility physicians and nurses by telephone follow-up their rehabilitation.

\section{Results}

Observed by the early group and other various thumb function and grip strength and FIM scores were better than control group $(\mathrm{P}<0.05)$, the recovery refers to the function of two groups of comparison, observation group is better than that of control group, the observation group 4 weeks after the nursing intervention of rehabilitation exercise adherence were superior to control group, $\mathrm{P}$ $<0.05)$.

Table 1: The evaluation comparison between fingers functional assessment, hand grip strength and FIM of two groups of patients'

\begin{tabular}{ccccccc}
\hline Indicators & $\mathrm{n}$ & $\begin{array}{c}\text { Thumb } \\
\text { function } \\
\text { score } \\
\text { (points) }\end{array}$ & $\begin{array}{c}\text { Each other } \\
\text { refers to } \\
\text { the } \\
\text { functional } \\
\text { score } \\
\text { (points) }\end{array}$ & $\begin{array}{c}\text { Grip } \\
\text { strength } \\
(\mathrm{kg})\end{array}$ & $\begin{array}{c}\text { FIM } \\
\text { (points) }\end{array}$ & $\begin{array}{c}\text { Recovery } \\
\text { time } \\
\text { (Weeks) }\end{array}$ \\
\hline $\begin{array}{c}\text { The } \\
\text { observation } \\
\text { group }\end{array}$ & 32 & $\begin{array}{c}8.65 \pm 0.9 \\
4\end{array}$ & $8.31 \pm 0.76$ & $\begin{array}{c}12.31 \pm 3 . \\
54\end{array}$ & $\begin{array}{c}40.17 \pm 4 . \\
12\end{array}$ & $\begin{array}{c}13.25 \pm 3.0 \\
2\end{array}$ \\
$\begin{array}{c}\text { The control } \\
\text { group }\end{array}$ & 32 & $\begin{array}{c}5.08 \pm 1.2 \\
6\end{array}$ & $4.87 \pm 1.26$ & $\begin{array}{c}4.35 \pm 1.0 \\
2\end{array}$ & $\begin{array}{c}31.28 \pm 2 . \\
46\end{array}$ & $\begin{array}{c}28.67 \pm 9.5 \\
6\end{array}$ \\
\hline
\end{tabular}


Table 2: Two groups of patients before and after the nursing intervention of rehabilitation exercise adherence

\begin{tabular}{|c|c|c|c|c|c|}
\hline Indicators & $\mathrm{n}$ & Time & The better & General & Poor \\
\hline \multirow{2}{*}{$\begin{array}{l}\text { The } \\
\text { observation } \\
\text { group }\end{array}$} & \multirow{2}{*}{32} & $\begin{array}{c}\text { Before } \\
\text { nursing } \\
\text { intervention }\end{array}$ & 18 & 9 & 5 \\
\hline & & $\begin{array}{l}4 \text { weeks } \\
\text { after nursing } \\
\text { intervention }\end{array}$ & 30 & 2 & 0 \\
\hline $\begin{array}{l}\text { The control } \\
\text { group }\end{array}$ & 32 & $\begin{array}{c}\text { Before } \\
\text { nursing } \\
\text { intervention } \\
4 \text { weeks } \\
\text { after nursing } \\
\text { intervention }\end{array}$ & 23 & 10 & 5 \\
\hline
\end{tabular}

\section{Discussion}

Operation treatment is the important way of hand trauma to the patient's postoperative outcomes, in addition, the degree of postoperative rehabilitation exercise and rivals function rehabilitation influential aspects.

\section{The aim of treatment for hand trauma}

Therapy of hand trauma purpose is not only required hand complete and beautiful appearance, more to win its functional recovery. This requires nursing staff must master and proficient in hand injury rehabilitation knowledge, and based on the damage degree of patients, parts, internal and external fixation, and so on and so forth to individualized rehabilitation plan for patients. Among them, the most important thing is to fully grasp the timing of the patients with functional exercise. Incidence of 28 patients with invalid are almost due to it's can't tolerate the pain and loss of hand function after surgery for the best chance of recovery. In addition, nursing staff should pay attention to patients in rehabilitation nursing of psychological adjustment to positive health status; to guide patients with love should be comprehensive and effectively implement functional exercise. For general hand injury with skin laceration, mild tissue contusion and pure single these injuries treated with general prognosis is good, however severe hand trauma, such as multiple fractures. Open comminuted fracture and tendon with vascular injury, serious injury, and the treatment is also very complex. Therefore, should pay attention to strengthen the opponents' trauma patients with postoperative rehabilitation care and functional exercise guidance.

\section{The trauma, early postoperative rehabilitation}

Trauma, postoperative rehabilitation of early intervention can effectively promote the improvement of hand function, reduce the degree of disability. Hand trauma cause dysfunction of the main reasons are: local hemorrhage, edema caused by soft tissue hardening and leg muscle adhesion, the adhesion caused by braking, joint surrounding soft tissue contracture, addiction scar contracture of skin damage, adhesion cause joint deformities. Joint damage caused by the joint rigidity, etc. So after hand trauma, the first thing to solve the problem of wound and swelling, early rehabilitation therapy (wound repair after 1 week) to alleviate edema, increasing local blood circulation, promote the wound healing and anti-infection ability is given priority to, to create conditions for other treatments. Main methods, postoperative mouth started decimeter wave without heat, erythematic dose exposure to the sun's ultraviolet rays, keep high level to the heart of hand, prevent infection, decimeter wave therapy can accelerate muscle leg healed, increase leg muscle tension strength, can increase muscular legs adhesion compliance area have obvious promoting regeneration of nerve functional recovery. Early active activities not break joints, wound conditions 
allow to give chemotherapy, audio electrotherapy, and ultrasonic therapy, can promote the addiction scar softening, restore the role of tissue elasticity.

First of all should make the patient care process opponent surgical disease will have a correct understanding of self monitoring patients fully involved in the treatment plan, in order to improve the treatment effect, improve the patients quality of life, the most ideal jointly participated the doctor-patient relationship is established. The process of implementation of the comprehensive nursing health education, through the interpretation of nursing workers education make both nurses and patients to build up mutual trust mutual cooperation degree can also be widely to improve doctor-patient relationship patients, lays the foundation for the patients with hand good functional recovery. In practice of nursing personnel need to strengthen the professional hand surgery health knowledge to improve language expression and emotional communication ability in order to improve the quality and effect of health education. A continuation of the discharged patients nursing service refers to the use of telephone, Internet and other information tools, between nurses and patients and their families for a purposeful interaction, for the purpose of promoting and safeguarding the health of patients, it is a kind of from the hospital to the extension of family supervision mode. Studies show hall a lot of patients after the home still have varying degrees of health questions, so patients after discharge has high accept disease related health education needs. And through this continuation of nursing service, can in the largest extent, meet the demand of patients' knowledge of rehabilitation information to build a good teaching platform, help to hospital in time to understand the patient's condition and function recovery, and continuity to the corresponding according to patients' medical help.

\section{The influence of nursing intervention opponents trauma of hand function recovery}

Hand function rehabilitation exercise process not only can cause local discomfort, and because of its is a long process, so the patient endurance of the demand is higher, and the rehabilitation of the patients with exercise adherence put forward higher requirements, so the patient's rehabilitation exercise adherence of intervention is very important. In view of the influence of nursing intervention for the treatment of patients with attitude, therefore in the process of intervention on the patients should pay attention to the choice of care model in the first place.

Strengthening nursing intervention on the basis of conventional nursing intervention is to strengthen the various procedures and details and the pattern of nursing development, it not only to the original details for further detailed and reinforcement, and intensive nursing intervention, in addition, the scope and form of care also widen further, so the degree of intervention on the patients and the deeper and more widespread.

In this study, we will strengthen the nursing intervention opponents trauma patients with postoperative rehabilitation exercise adherence to observe the influence of the analysis, and comparing with conventional nursing care, the results show that improved more effective nursing intervention to improve the patient's rehabilitation exercise adherence, and the improvement of the patients with different degree of social support were greater than the conventional nursing intervention, thus affirms the opponents trauma postoperatively, the effect and the necessity of strengthening the nursing intervention.

Burn care to the success of the new standards includes two aspects of the patient's survival and the quality of life for a long time. Burn patients after life is guaranteed, more attention to burn after the patient's mouth often life ability, comprehensive health (including physical, psychological and social health, etc.) as well as the patients after the return to society, such as employment, marriage, income, etc. The quality of life is for a long time. Hand the high injury rate and high morbidity of the serious influence the patient's quality of life, but also bring heavy burden on patients, families and society, highlighting the hand area of the burn patient the necessity and importance of rehabilitation nursing care. Many scholars at home and abroad of burn patients in rehabilitation nursing, psychological intervention and health education measures are studied, think this a series of measures to improve the hand burn patients quality of life has a positive effect for a long time. At 
home and abroad about the solutions of rehabilitation training is various, have not set up relevant hand injuries, the standard method or guide.

\section{Conclusion}

The hand trauma after timely surgical treatment is the prerequisite of hand function recovery; physical factors, sport therapy, homework therapy, and rehabilitation project of early intervention can improve the activity, and promote the recovery of hand function, worthy of clinical popularization and application.

\section{Acknowledgement}

This research was financially supported by the National Science Foundation.

\section{References}

[1] Jason Wasiak, Margaret McMahon, Stefan Danilla, Anneliese Spinks, Heather Cleland, Belinda Gabbe. Measuring common outcome measures and their concepts using the International Classification of Functioning, Disability and Health (ICF) in adults with burn injury: A systematic review[J]. Burns . 2013 (6)

[2] Ali Akbar Mohammadi, Ali Reza Bakhshaeekia, Saeed Marzban, Siroos Abbasi, Ali Reza Ashraf, Mohammad kazem Mohammadi, Hamid Reza Toulide-ie, Ahmad Reza Tavakkolian. Early excision and skin grafting versus delayed skin grafting in deep hand burns (a randomised clinical controlled trial)[J]. Burns . 2012 (1)

[3] Erika Davis Sears,Kevin C. Chung. Validity and Responsiveness of the Jebsen-Taylor Hand Function Test[J]. Journal of Hand Surgery . 2010 (1)

[4] T. Quinn,J. Wasiak,H. Cleland. An examination of factors that affect return to work following burns: A systematic review of the literature[J]. Burns. 2012(7)

[5] Asgjerd LitleréMoi, Hallvard Andreas Vindenes, EvaGjengedal. The experience of life after burn injury: a new bodily awareness[J]. Journal of Advanced Nursing. 2012 (3)

[6] Claire Phillips, Anna Fussell, Nichola Rumsey. Considerations for psychosocial support following burn injury-A family perspective[J]. Burns. 2013 (8)

[7] Peter C. Esselman,Brett D. Thombs, Gina Magyar-Russell,James A. Fauerbach. Burn Rehabilitation: State of the Science[J]. American Journal of Physical Medicine \& Rehabilitation. $2012(4)$

[8] Etienne G Krug. Injury surveillance is key to preventing injuries[J]. The Lancet. 2012 (9445)

[9] GEROLD STUCKI,THOMAS EWERT,ALARCOS CIEZA. RETRACTED: Value and application of the ICF in rehabilitation medicine[J]. Disability \& Rehabilitation. 2013 (11-12)

[10] Soumya Ghosh,Ritesh Sinha,Soma Datta, Arunima Chaudhuri, Chinmoy Dey, Abhinay Singh. A study of hand injury and emergency management in a developing country[J]. International Journal of Critical Illness and Injury Science. 2013 (4). 